\title{
CRIAÇÃO COMPARTILHADA DE UM JOGO: UM INSTRUMENTO PARA O DIÁLOGO SOBRE SEXUALIDADE DESENVOLVIDO COM ADOLESCENTES
}

\section{Shared creation of a game: a tool for dialogue about sexuality developed with adolescents}

\author{
Maria José Nogueira ${ }^{1}$ \\ Samuel Barcelos ${ }^{2}$ \\ Héliton Barros ${ }^{3}$ \\ Virgínia Torres Schall ${ }^{4}$
}

\begin{abstract}
Resumo: Este trabalho descreve o processo de desenvolvimento de um Jogo Educativo, desenvolvido, de forma compartilhada, com adolescentes da Vila Cafezal, comunidade em uma área de favelas de Belo Horizonte. Por meio de oficinas em grupos operativos, criou-se um espaço de diálogo sobre sexualidade e gravidez na adolescência. Fazem parte do jogo: (1) oitenta cartas de perguntas e respostas; (2) um baralho de reflexão, e (3) um baralho de locais, demarcando espaços públicos da Vila Cafezal. Constatou-se que o processo desenvolvido auxiliou os jovens na construção de conhecimento, no diálogo e compreensão sobre atitudes de cada gênero. Tanto o processo descrito no presente artigo quanto o material produzido podem ser utilizados como alternativas para se criar um ambiente saudável e interativo para se trabalhar os temas referentes a sexo e sexualidade, na perspectiva requerida pelos Parâmetros Curriculares Nacionais (PCN) e pelas demandas do Serviço Único de Saúde (SUS).

Palavras-chave: Adolescência. Sexualidade. Educação em saúde. Jogo educativo. Saúde reprodutiva.

This paper describes the process of developing an educational game in collaboration with adolescents from Cafezal Village, a community of a slum area of Belo Horizonte, Brazil. The objective of this study was to create a space for dialogue concerning sexuality and teenage pregnancy through workshops in operative groups. The game consisted of: (1) 80 question/answer cards; (2) 15 thinking cards and; (3) 15 territory cards showing public places that belong to Cafezal Village. It was found that the process helped the youth in the construction of knowledge through dialogue and understanding the attitudes of each gender. The process described in this article and the material produced can be used as alternatives to create a healthy and interactive environment to work through the issues related to gender and sexuality within the perspective of the Brazilian National Curricular Parameters (PCN) and the demands of the Brazilian Public Health System (SUS).
\end{abstract}

Keywords: Adolescence. Sexuality. Health education. Educational game.

\footnotetext{
${ }^{1}$ Doutora em Ciências da Saúde. Pesquisadora, Laboratório de Educação em Saúde, Centro de Pesquisa René Rachou, Fiocruz, Belo Horizonte, MG, Brasil. <maria.nogueira@esp.mg.gov.br>

${ }^{2}$ Graduando em Ciências Sociais. Bolsista, Laboratório de Educação em Saúde, Centro de Pesquisa René Rachou, Fiocruz, Belo Horizonte, MG, Brasil.samuelmbarcelos@cpqrr.fiocruz.br

${ }^{3}$ Mestre em Ensino em Biociência e Saúde. Bolsista, Laboratório de Educação em Saúde, Centro de Pesquisa

René Rachou, Fiocruz, Belo Horizonte, MG, Brasil. helitonbh@gmail.com

${ }^{4}$ Doutora em Educação. Pesquisadora-chefe, Laboratório de Educação em Saúde, Centro de Pesquisa René Rachou, Fiocruz, Belo Horizonte, MG, Brasil. vtschall@cpqrr.fiocruz.br

${ }^{1}$ Escola de Saúde Pública de Minas Gerais

Av. Augusto de Lima, 2061

Barro Preto - Belo Horizonte, MG

30.190-002

941

Ciência $\mathfrak{E}^{3}$ Educação, v. 17, n. 4, p. 941-956, 2011
} 
Nogueira, M. J. et al.

\section{Introdução}

A Orientação Sexual na Escola é prática defendida e orientada pelo Ministério da Educação (MEC) nos Parâmetros Curriculares Nacionais (PCN), como eixo transversal ao currículo (BRASIL, 1998a). O documento considera a escola como parceira da família e da sociedade na promoção da saúde das crianças e dos adolescentes, e atribui, às escolas, a corresponsabilidade de orientação da criança desde o pré-escolar ao Ensino Fundamental. "No diálogo entre a escola e as famílias, pretende-se que a sexualidade deixe de ser tabu e, ao ser objeto de discussão na escola, possibilite a troca de ideias entre esta e as famílias" (BRASIL, 1998a, p. 304). Por outro lado, a literatura também aponta a dificuldade que escolas e famílias ainda apresentam para abordar o tema da sexualidade com crianças e jovens (ALTMANN, 2001; SALLAS; QUINTANA, 2002; VILLELA; ARILHA, 2003; WEREBE, 1998; GUIMARÃES; VIEIRA; PALMEIRA, 2003; BORUCHOVITCH, 1992; HERNÁNDEZ, 2000). Assunto polêmico na esfera pública e na esfera privada, a sexualidade, tratada sem o descobrir do próprio "eu" e do reconhecimento do outro, torna-se pouco significativa, não alcançando discussões mais profundas sobre valores individuais e sociais, o que de fato importa no processo educativo. Desse modo, reconhece-se que uma abordagem transdisciplinar da sexualidade requer boa formação dos professores e profissionais de saúde, e materiais educativos adequados.

O cenário nas escolas é preocupante, pois não se percebe a vinculação dos conteúdos ao contexto dos escolares, quando se tratam de temas que se destinam a auxiliar o jovem na compreensão do próprio corpo e de suas relações amorosas, bem como do desenvolvimento da responsabilidade pela sua saúde e do outro com quem se relaciona (PINTO, 1997; BUENO, 2001; SCHALL, 2005). Para temas como a sexualidade, que requerem não só domínio do conhecimento biológico, mas reflexão sobre a vida e o ambiente em que se vive, construir novos conhecimentos demanda processos singulares e criativos, que preparem o cidadão para o seu viver cotidiano (HERCOWITZ, 2002; MACHADO et al., 2007).

Em relação às escolas, o livro didático é um dos materiais mais disponíveis e utilizados pelos professores em todo o território nacional. Avaliações recentes de alguns tópicos dos livros de ciências, no que se refere à saúde, revelam incorreções e concepções incorretas (MOHR, 2000; SILVA; CARVALHO, 2005).

Pensou-se, então, em desenvolver estratégias e materiais educativos que pudessem dar lugar a um processo de construção de conhecimento que estivesse estreitamente vinculado à realidade e à participação dos jovens. No presente artigo são descritos: as oficinas, a produção compartilhada do jogo, o produto obtido e algumas reflexões sobre o processo e suas perspectivas de replicação em espaços educativos e de saúde.

\section{Fundamentos teóricos da pesquisa}

$\mathrm{Na}$ área da saúde, os jogos têm sido referidos como alternativas que permitem alcançar, de forma prazerosa e motivante, os objetivos de pesquisas, da educação e da divulgação científica. Experiências internacionais (PAPERNY; STARN, 1989; SCHALL et al., 1999; AMARO et al., 2006; WIDEMAN et al., 2007) revelam a potencialidade do uso dos mesmos nas estratégias de educação e promoção da saúde. Segundo Wideman (2007), os jogos podem 
proporcionar experiências em vários contextos que potencializam a compreensão de conceitos complexos "sem perder as conexões entre os problemas reais e as ideias abstratas que podem ser usadas para resolvê-los" (SHAFFER et al., 2004 apud WIDEMAN, 2007, p. 18).

Segundo Vygotsky (1984), o jogo facilita o desenvolvimento da imaginação e da criatividade, ampliando ou criando novas relações entre o campo do significado e o campo da percepção visual. Para Macedo (1995), os jogos educativos têm grande importância para a produção do conhecimento, no sentido de serem reveladores do como e o porquê das coisas. De acordo com Monteiro, Rebello e Schall (1994), os jogos proporcionam maior interação e espaço para discussão entre as pessoas, e servem de estímulo à discussão de temas-tabus, polêmicos, graves e atuais, que, geralmente, não são abordados de forma mais ampla dada a sua complexidade. No âmbito da sexualidade, a literatura aponta a dificuldade que escolas e famílias ainda apresentam para abordarem a temática com crianças e jovens (ALTMANN, 2001; SALLAS; QUINTANA, 2002; VILLELA; ARILHA, 2003; WEREBE, 1998; GUIMARÃES, 2003; BORUCHOVITCH, 1992; HERNÁNDEZ, 2000), o que requer investimento para criar espaços e estratégias mais efetivas.

Ao se aproximar jogo e educação, compartilha-se com as visões mais contemporâneas de educação, que ressaltam a importância da iniciativa e participação dos alunos no processo de aprendizagem. Desse modo, encontrou-se, nos postulados filosóficos e metodológicos de Enrique Pichon-Rivière e Paulo Freire, a ancoragem necessária ao estudo.

Embora apresentem visões distintas, esses autores se aproximam à medida que compartilham de um modelo educativo e similaridades na interpretação do processo de ensinoaprendizagem. Pichon-Rivière (2000), ao articular o materialismo dialético e a psicanálise, apresenta uma discussão importante sobre grupos operativos e educação. Postula uma didática que emerge do campo da psicologia social, destinada não só a comunicar conhecimentos, mas desenvolver e modificar atitudes. Freire (1976), na perspectiva pedagógica de sua prática, traz os pressupostos de uma educação conscientizadora e problematizadora, na qual, palavras geradoras, círculo de cultura e diálogo são conceitos fundamentais. Segundo o autor, é impossível fazer uma reflexão sobre educação sem refletir sobre o próprio homem. Ressalta, assim, a necessidade de se romper com a ideia clássica da prática educacional como um ato de transferência de conhecimento.

Para Freire (1974, p. 56), aprender é compartilhar uma "leitura do mundo", ou, nas palavras de Pichon-Rivière (2000, p. 38), aprender é realizar uma "leitura da realidade". Tal perspectiva aproxima-se da visão sócio-histórica do conhecimento e da sala de aula, na qual o aluno tem papel ativo e o conhecimento é compartilhado e construído pelas ações conjuntas dos participantes da interação (VYGOTSKY, 1984).

Na tarefa de alfabetização de adultos, Freire (1976) ressalta a importância de se buscarem, no cotidiano dos "alfabetizandos", as palavras geradoras, por meio das quais iniciarão o processo de alfabetização. As palavras geradoras não devem ser escolhidas simplesmente por sua combinação fonética, conforme as cartilhas são produzidas, sem levar em consideração as diferenças socioculturais e desconsiderando a capacidade dos indivíduos de significarem e ressignificarem.

Para Pichon-Rivière (2000, p. 78), cabe ao coordenador "pensar com o grupo", criando um vínculo entre o grupo e o campo de sua tarefa, no sentido de criar, manter e fomentar a comunicação. Para o autor, a comunicação grupal é possível pela existência de um esquema 
Nogueira, M. J. et al.

conceitual, referencial e operativo de caráter grupal, ou seja, à semelhança de esquemas referenciais usados para codificar e decodificar a mensagem, permitindo que o receptor compreenda a mensagem emitida pelo transmissor. O aprendizado no grupo é reforçado nas ideias de Freire, por meio do círculo de cultura, ou seja, o aprender em grupo no contexto do grupo. No Círculo de Cultura, “[...] em lugar de professor, com tradições fortemente 'doadoras', o Coordenador de Debates. Em lugar de aula discursiva, o diálogo. Em lugar de aluno, com tradições passivas, o participante do grupo" (FREIRE, 1974, p. 103).

Assim, a opção teórico-metodológica do presente estudo incorpora três premissas básicas: o conhecimento deve ser produzido na interação dos sujeitos comunicantes; os símbolos (palavras, gestos, objetos) utilizados nos materiais educativos devem ser contextualizados no sentido de refletirem os anseios, preocupações e dúvidas do público-alvo; necessidade de fortalecimento de vínculo entre os profissionais de saúde e usuários - no caso específico, os adolescentes - e entre alunos e professores. Considerando tais perspectivas, optou-se pela pesquisa participante, como descrito a seguir.

\section{Metodologia da pesquisa}

Para ancorar os pressupostos teóricos que balizaram o estudo, optou-se pela pesquisa participante. Para Brandão (1985), a pesquisa participante é um enfoque de investigação social que busca a participação da comunidade na análise de sua própria realidade, com objetivo de promover a participação social para o benefício dos participantes. Isso significa que as práticas que constituem o social e os referenciais que lhe dão sentido vão se produzindo concomitantemente, uma vez que o conhecimento e a ação sobre a realidade são constituídos no curso da pesquisa de acordo com as análises e decisões coletivas, dando, à comunidade participante, uma presença ativa no processo. Para instrumentalizar a prática pretendida, escolheu-se a técnica de grupos operativos na perspectiva de Pichon-Rivière (2000).

As oficinas temáticas foram utilizadas como instrumento para viabilizar e dinamizar o processo de grupo. Afonso (2003) destaca as oficinas como técnicas de intervenção psicossocial, uma ferramenta de trabalho na área de educação em saúde que possibilita superar o caráter vertical de transmissão de conhecimento recorrente nas práticas pedagógicas tradicionais.

\section{Espaço de investigação}

A Vila Cafezal faz parte do Aglomerado da Serra, situado no município de Belo Horizonte, MG. De acordo com dados censitários (IBGE, 2001), a região possuía, em 2001, uma população de 10.481 habitantes, sendo 92,6\% cadastrados na Unidade Básica de Saúde Vila Cafezal. É constituída de 49,1\% de homens e 50,9\% de mulheres, sendo (47,9\%) de pessoas adultas entre 20 e 59 anos. A população da área de abrangência é composta por um grande número de jovens (até 19 anos), com $1^{\circ}$ grau incompleto, sem plano de saúde, com renda familiar até três salários. A região é conhecida pelos altos índices de violência e encontra-se dentro dos critérios de alto risco estabelecidos pela Secretaria Municipal de Saúde de 
Belo Horizonte no Índice de Vulnerabilidade à Saúde (IVS) - indicador composto, que associa diferentes variáveis socioeconômicas e de ambiente num indicador sintético, para analisar as características de grupos populacionais vivendo em determinadas áreas geográficas.

Quatro Equipes de Saúde da Família (ESF) estão designadas para o atendimento de 2.442 famílias (aproximadamente, seiscentas familias por equipe), sendo formadas por: um médico, uma enfermeira, dois auxiliares de saúde e cinco ou seis Agentes Comunitários de Saúde (ACS), recrutados na própria comunidade. Para facilitar a identificação pelos respectivos usuários, as equipes foram nomeadas com cores diferentes (roxa, laranja, azul e verde). Para a realização das atividades do projeto, escolheu-se a equipe ESF Roxa, por já estar envolvida em trabalhos com os adolescentes.

\section{Seleção do grupo}

Solicitou-se, aos ACS da Equipe Roxa, que preenchessem a ficha cadastral de todos os moradores com idade entre dez e 14 anos das famílias por eles atendidas. Ao final, foram cadastrados 126 adolescentes (54 meninos e 72 meninas). Para selecionar o grupo, foram utilizados os seguintes critérios de inclusão: (a) estar cadastrado no Programa de Saúde da Família da Equipe Roxa na Vila Cafezal; (b) não estar participando de outro projeto social; (c) não estudar na parte da tarde. Após aplicação desses critérios, tínhamos 35 jovens. Foi realizado um sorteio aleatório, na presença dos ACS e de uma médica do posto de saúde, de vinte adolescentes (dez meninos e dez meninas). Cada ACS anotava o nome dos adolescentes que faziam parte de sua área de atuação. Ao final, outro critério de exclusão foi adicionado, após o depoimento dos ACS, que sugeriram descartar quatro adolescentes, uma vez que os mesmos estavam envolvidos com drogas e não moravam com as famílias, o que dificultava o acesso aos mesmos. Os agentes comunitários ficaram responsáveis por levar, pessoalmente, o convite para os pais ou responsáveis e para os adolescentes. O grupo que aderiu ao estudo totalizou seis meninos e 11 meninas. Apesar de o convite ter sido feito para dez meninos, a adesão dos mesmos foi menor, fato apontado na literatura (RENA, 1999).

\section{Estrutura das oficinas}

As oficinas foram dirigidas para o público adolescente (dez a 14 anos) da área de ação da ESF Roxa, tendo incluído os 16 participantes do grupo escolhido. Foram realizados 35 encontros no posto de saúde, às sextas-feiras, de 14 às 17 horas, no período de abril de 2006 a março de 2007. Cada encontro foi dividido em três momentos: apresentação, reflexão do tema gerador do encontro e avaliação. Os temas geradores foram eleitos em parceria com os jovens, no primeiro encontro, por meio de uma dinâmica específica, na qual os adolescentes elegeram temas ligados à saúde reprodutiva e adolescência sobre os quais tinham dúvidas e curiosidades. A partir dessa demanda, os pesquisadores confrontaram os temas com as possibilidades metodológicas e recursos humanos envolvidos no projeto. Os temas eleitos foram: namoro, métodos contraceptivos, primeira relação sexual, doenças sexualmente transmissíveis, corpo humano, gravidez na adolescência e drogas. 
Nogueira, M. J. et al.

\section{Oficinas com grupos operativos: produção compartilhada de material educativo}

O primeiro encontro teve como objetivo iniciar um processo de constituição de uma identidade e integração grupal. Nesse momento, estabeleceu-se o "contrato" entre os membros do grupo e a coordenação através do acordo de regras fundamentais. No segundo encontro, foi proposta a discussão a respeito das diferenças entre homens e mulheres: por que estas diferenças se transformam em desigualdades?

No terceiro encontro, foi realizada uma técnica para se conhecer o corpo reprodutivo - feminino e masculino - de forma participativa e de modo a perceber que, do corpo, também fazem parte as características psicológicas, a história pessoal e as relações que se estabelecem com as pessoas, o meio social e a cultura. Foram discutidos mitos e tabus relacionados ao corpo da mulher e do homem. Nos dois encontros posteriores, através de um questionário de verdadeiro $(\mathrm{V})$ ou falso $(\mathrm{F})$, discutiram-se, com o grupo, questões relacionadas ao tema sexo e sexualidade, com o objetivo de esclarecer dúvidas e estimular a reflexão. Ver, tocar e examinar os diversos métodos contraceptivos - pílula, preservativos masculino e feminino, DIU, diafragma - foi o tema do sexto encontro. Os meninos e meninas, separadamente, tiveram a oportunidade de obter informações e esclarecer dúvidas a respeito do tema. No sétimo e oitavo encontros, através do recurso do jogo Zig-Zaids, produzido pela Fundação Oswaldo Cruz (SCHALL et al., 1999), procurou-se criar um ambiente descontraído para discutir a temática das DST/AIDS.

No nono encontro, um grupo de meninas e meninos entrevistaram pais e mães adolescentes. Por intermédio do relato da experiência, procurou-se debater a temática da paternidade e maternidade. O décimo encontro teve como foco principal rever os objetivos iniciais do projeto que haviam sido propostos pela equipe e negociados com o grupo. Procurou-se reafirmar o compromisso e avaliar as expectativas dos adolescentes em relação à elaboração do jogo e dos vídeos de animação. Foi feita uma avaliação e discutido o comprometimento na participação das atividades posteriores. Os adolescentes foram distribuídos em dois grupos, segundo a escolha dos mesmos, para a realização do jogo e dos vídeos de animação. No presente artigo, são apresentadas as atividades realizadas pelo grupo que participou do desenvolvimento do jogo educativo. A experiência com os vídeos educativos foi descrita por Nogueira (2003).

O projeto foi aprovado pelos comitês de ética do Centro de Pesquisa René Rachou, da Fundação Oswaldo Cruz (CPqRR/Fiocruz Minas), e da Prefeitura Municipal de Belo Horizonte.

\section{Resultados e discussão}

\section{Aspectos estruturais do jogo na percepção dos adolescentes}

Avedon e Sutton-Smith (1971) identificaram nove elementos estruturais em jogos: propósito ou razão, procedimentos de ação, regras que governam a ação, número de jogadores requeridos, papéis dos participantes, habilidades e qualificação, padrões de interações dos 
participantes, cenário físico e ambiente necessário, e equipamento para a sua prática. No primeiro momento deste trabalho, os adolescentes citam alguns desses elementos como estruturantes do jogo, tais como: objetivo, regras, o campo, no qual ele seria jogado (no caso, um tabuleiro), pinos para representarem os jogadores, perguntas e respostas, número de participantes. O padrão de interação entre os participantes, bem como os papéis e a definição das regras foram elucidados ao longo do processo.

Os adolescentes citam como inerente ao jogo: o caráter de disputa, a presença de regras e a premiação. Segundo Mitchell e Savill-Smith (2004), a competição, contra si mesmo ou contra outros, aumenta a percepção de conquista e eficácia do jogador. Os adolescentes destacaram que poderiam produzir um jogo no qual a disputa seria entre meninos e meninas: "o jogo tem que ser uma competição com oponentes masculinos e femininos com regras e prêmios"; "tem que ter disputa entre meninos e meninas". Tal fato é bastante interessante, uma vez que a literatura da área (HERNÁNDEZ, 2000; PORTELLA, 2004) demonstra que, na maioria das vezes, os adolescentes buscam informações e discutem temas referentes à sexualidade com os pares, o que dificulta o entendimento de questões referentes ao sexo oposto. Em nosso estudo, o grupo destacou a necessidade de se criarem cartas diferenciadas para homens e mulheres, "perguntas de homens" e "perguntas de mulher", o que aponta para uma visão recorrente que atribui conhecimentos e papéis específicos segundo o gênero. Em estudo etnográfico, Silva et al. (2006) demonstram como a segregação é uma característica comum nos grupos de brincadeira, sendo expressivamente maior entre os meninos.

\section{O tema sexualidade na dimensão lúdica e educativa}

Segundo Kishimoto (2008), a possibilidade de aprendizado e o respeito à natureza do lúdico, garantida pelo ato de jogar, remete ao conceito de jogo educativo. Em nosso estudo, as duas dimensões aparecem nas falas dos adolescentes. A dimensão lúdica foi representada pelas palavras "lazer", "brincadeira" e "diversão", o que, na literatura, é representado pelo caráter "não sério do jogo", em contraponto com a dimensão do trabalho (HUIZINGA, 1981).

Os adolescentes também ressaltam o caráter informativo e de aprendizado presente nos jogos. Em suas próprias palavras o jogo serviria para "tratar um assunto", "dar um cuidado especial a um assunto". Quando indagados a respeito da temática que gostariam de "tratar" no jogo, destacaram a temática do sexo e da sexualidade, justificando a dificuldade encontrada nas esferas da família e da escola para dialogar sobre tais assuntos. O relato dos adolescentes é coerente com a literatura da área (ALTMANN, 2001; SALLAS; QUINTANA, 2002; VILLELA; ARILHA, 2003; WEREBE, 1998; GUIMARÃES, 2003; BORUCHOVITCH, 1992, HERNÁNDEZ, 2000).

"Não converso com nenbum dos dois. Minha mãe não conversa, ela xinga. Eé difícil, não é fácil não, com minha mãe é difícil, porque se a gente começa a conversar com ela sobre alguma coisa assim que ela acha errado, ela começa a xingar, não espera a gente acabar de explicar. Ela só dá conselho xingando". (Feminino, 15 anos)

"Com nenbum dos dois". (Feminino, 12 anos) 
Nogueira, M. J. et al.

O "ato de jogar" e o "jogo", na percepção dos adolescentes, possibilitariam o desenvolvimento de atitudes, tais como: "união", "companheirismo" e "solidariedade"; estimulando o raciocínio e facilitando o aprendizado de conceitos e noções. O jogo destaca-se pelo papel de possibilitar aprendizagem instruída, essencialmente vygotskyniana, na qual aprendizes internalizam as instruções e as usam subsequentemente para autorregular sua atenção, sua memória e outras funções cognitivas (VYGOTSKY, 1984). Torres, Hortale e Schall (2003) destacam a experiência de jogos educativos para grupos operativos como uma técnica que facilita a integração grupal e potencializa a construção de novos conhecimentos. Perspectiva semelhante é apontada por Amaro et al. (2006) ao descrever a experiência do uso de jogos educativos entre crianças com a finalidade de elaborar novos conhecimentos acerca de uma dieta saudável.

\section{O desenvolvimento compartilhado do jogo}

Assim feito, os próprios adolescentes construíram um protótipo de cartolina com o caminho a ser percorrido pelos jogadores e, também, o local no qual se passaria toda a brincadeira, no caso, a própria Vila Cafezal. A ideia de transpor, para o tabuleiro, o espaço físico da Vila foi justificada, pelos adolescentes, pela necessidade de ressignificar a região onde moram. Muitas vezes, a Vila Cafezal é retratada, através dos meios de comunicação, vinculada a notícias de pobreza, tráfico de drogas e violência. Desse modo, produziu-se um mapa da região, detalhando os locais eleitos por eles como os mais importantes da vila, que compõem o baralho de cartas de locais. Foi sugerido por uma adolescente, e aceito pelo grupo, que o microônibus amarelo, que circula dentro da Vila - transporte público municipal -, identificado pelo número 103, seria reproduzido para percorrer o trajeto do tabuleiro.

Tal fato explicita a possibilidade de, em determinado contexto e mediados pela linguagem, os indivíduos poderem captar a realidade transformando-a em objeto de seus conhecimentos. Para a abordagem sócio-histórica, o papel do professor é fundamental nesse processo. No conceito de mediação, proposto por Vygotsky (1984), uma nova relação entre alunos e professores é gerada, sendo o professor um mediador entre o aluno e seu conhecimento. Em Freire (1976), aparece a ideia do professor que pensa com o aluno, e não aquele que pensa para o aluno, sendo a compreensão da realidade fundamental: "Quando se compreende a realidade, pode-se desafiá-la e procurar possibilidades de soluções. O homem deve tentar transformar a realidade para ser mais" (FREIRE, 1976, p. 119).

Segundo Abduch (1999), com os adolescentes, a técnica de grupos operativos tem sido indicada como instrumento para desenvolvimento dos fatores básicos e elementares de prevenção, que são: autoestima, juízo crítico, plano de vida e criatividade. Capacidades essas que, se desenvolvidas grupalmente, tornam-se fatores protetores aos riscos a que os jovens estão expostos atualmente, como: morte por causas externas, gravidez acidental, contaminação com o vírus da imunodeficiência humana, adição a drogas, entre outros. A técnica de grupos operativos pode ser considerada um instrumento eficiente por se tratar de uma didática horizontal que considera o indivíduo agente ativo, responsável e engajado no processo de mudança, na medida em que suas necessidades pessoais e comunitárias são levadas em consideração. Restrepo (2001) destaca a necessidade de conhecermos as experiências individuais, o ambiente físico e social, bem como a influência da cultura na relação dos indivíduos com o processo saúde-doença. 
Criação compartilhada de um jogo: ...

\section{Perspectivas de gênero na dinâmica de criação do jogo}

No momento de se discutirem as temáticas, percebe-se que as adolescentes são mais curiosas, fazem mais perguntas e são mais prolixas ao formulá-las ou respondê-las. Divagam mais e, com frequência, abstraindo-se do tema em discussão, fazem perguntas sobre assuntos correlatos, sobretudo, ligados à questão afetiva e métodos contraceptivos: "Depois que um homem transa com uma mulher pela primeira vez, ele tem obrigação de cuidar dela para sempre, mesmo que ela não queira, mas por preconceito dos pais?"; "O que o bomem e a mulher devem fažer para que a relação dê certo?" Há uma forte tendência ao interesse por assuntos relacionados aos bebês, nascimento, vida intrauterina:"Por que saiu uma água branca dos seios das mães?"; "Bebida alcoólica faz mal para o bebê?"

Os adolescentes são mais objetivos, menos prolixos, se interessam pelos assuntos ligados à questão física, à masculinidade; e são menos atentos a detalhes: "Um homem pode fazer sexo por 24 horas?"; "Sexo anal causa doenças?"; "Masturbação interfere na vida sexual?".

Os achados são coerentes com pesquisas da área (AFONSO, 2001; HERNÁNDEZ, 2000; PORTELLA, 2004). Em pesquisa realizada entre adolescentes de 14 a 20 anos, em Belo Horizonte, Afonso (2001, p. 215) destaca que "[...] as mulheres respondem melhor às questões sobre contracepção e os homens a questões sobre doenças sexualmente transmissíveis".

Em nosso estudo, as perguntas ligadas ao relacionamento sexual e gravidez foram abundantes entre as adolescentes: "A primeira vez engravida?"; "Quanto tempo o esperma dura no corpo da mulher?"; "A mulher pode engravidar quando está menstruada?"; "É normal ter dor durante a relação?"

Em relação às DST e Aids, as meninas foram menos questionadoras, em contrapartida, mobilizaram-se para perguntas sobre métodos contraceptivos, manifestando preocupações sobre o uso correto e a segurança dos mesmos: O diafragma é seguro? Como se usa a pílula? Pílula é um método seguro para adolescente? A tabelinha pode falhar? Entre os adolescentes do sexo masculino, predominam as questões relacionadas às doenças e à masculinidade: "A mulher pode beber o esperma?"; "Sexo anal causa doença?"; "A masturbação é prejudicial, 'dá' espinha?”; "Existe um doença chamada Sindrome do Sexo?"

A natureza das questões colocadas pelos adolescentes nos faz refletir a respeito do processo de socialização nas sociedades contemporâneas, especialmente na família, que ainda é marcado pela clássica divisão de papéis segundo o gênero. Estudos como o de Oliveira, Bilac e Muzskát (2000) apontam para a clássica distribuição em relação às responsabilidades reprodutivas, cabendo, às mulheres, mais responsabilidades, e, aos homens, mais autonomia. Em pesquisa realizada entre adolescentes de 14 a vinte anos, em Belo Horizonte, Afonso (2001, p. 215) destaca que no que se refere à temática da anticoncepção: “[...] as mulheres mostram scores de informação mais altos do que os homens, talvez por que sejam, em nossa cultura, consideradas responsáveis pela questão da concepção e da contracepção". Em pesquisa no município de Duque de Caxias, no Rio de Janeiro, Portella et al. (2004) destacam que a contracepção é percebida pelos homens como responsabilidade feminina, o que os leva a não conversar ou negociar o seu uso com as parceiras.

A proposta do jogo poderá preencher tal lacuna, podendo ser o momento de aproximação e disputa feita de maneira saudável, fazendo com que todos os participantes possam alcançar ganhos significativos, que estão além do simples prazer de jogar e competir. O fato de meninos e meninas jogarem e competirem no mesmo espaço garante a representação dos 
Nogueira, M. J. et al.

sexos, podendo ter resultados positivos para as relações de gênero (CRUZ; CARVALHO, 2006).

\section{As cartas do jogo: elaborando os baralhos}

Uma vez analisadas, as informações foram incluídas no jogo de maneira lúdica e criativa, evitando, por exemplo, desenhos e textos que trouxessem informações equivocadas, como, também, o uso do grotesco. Ao final, foram selecionadas 80 perguntas contendo as respectivas respostas, distribuídas nas seguintes temáticas: sexo e sexualidade, DST/Aids, gravidez e métodos contraceptivos. Desse modo, as dúvidas poderão ser compartilhas entre os e as adolescentes, na tentativa de se propiciar uma reflexão acerca da clássica divisão de assuntos femininos e masculinos que possam contribuir para o estabelecimento de relações mais igualitárias entre os gêneros.

Todas as respostas foram analisadas por dois ginecologistas, uma psicóloga e uma socióloga, para garantir correção científica, linguagem acessível aos jovens e objetividade, evitando textos longos e cansativos. Além do tema principal do projeto, foi de escolha dos próprios adolescentes incluírem assuntos que se apresentam em seu cotidiano. Foram elaboradas 12 cartas que constituiriam o baralho "Reflexão", abordando: o uso do preservativo, a decisão em relação à primeira relação, a virgindade, o uso de drogas, violência, dentre outros.

Os locais da Vila Cafezal que foram destacados pelos adolescentes compuseram o baralho de cartas de locais: posto de saúde, escola, igrejas católica e protestante, drogarias, a caixa d'água, o banquinho em frente à praça, a praça de esportes e as associações beneficentes. Os adolescentes criaram textos e imagens para representá-los. Os textos frisam a questão da não-violência: "não é um local perigoso"; "não tem violência lá"; "não é um lugar violento"; "não tem brigas lá". Tal fato nos remete para a preocupação dos mesmos em quebrar a visão recorrente de que o local é violento e perigoso. Em vários momentos, a descrição, no grupo, se aproximou muito de estereotipias perpassadas por questões ideológicas. O papel do coordenador foi relevante no sentido de balizar a discussão e criar um espaço de diálogo para ressignificar, de forma conjunta, os conceitos e símbolos trazidos pelo grupo, instaurando um espaço semelhante ao Círculo de Cultura.

\section{Protótipo do Jogo TransAção}

O jogo é composto de: oito pinos coloridos, um dado, oito ônibus, um tabuleiro, cartas perguntas e respostas (baralho verde), cartas de reflexão (baralho amarelo), cartas de locais (baralho roxo). Podem participar, no mínimo, duas pessoas ou duas duplas, e, no máximo, oito pessoas ou quatro duplas. As cartas de perguntas e respostas (baralho verde) e as cartas de reflexão (baralho amarelo) devem ser embaralhadas juntas e dispostas com o texto virado para baixo em lugar acessível para todos os jogadores, formando um monte. $O$ baralho de locais (baralho roxo) deve ser colocado também em local acessível para todos os jogadores. Os ônibus devem ser colocados no tabuleiro em local reservado, correspondente à casa "Ponto de Ônibus". Os pinos coloridos serão posicionados na entrada, sendo cada cor correspondente a um jogador ou uma dupla. Inicia-se o jogo com cada participante lançando o dado, sendo que aquele que alcançar o maior número dará início ao jogo. A partir disso, o jogo deve 
seguir em sentido horário. Vencerá o jogo aquele jogador ou dupla que chegar primeiro na última casa. É necessário que o jogador ou dupla tire o número exato de casas até atingir a casa final. Se faltarem cinco casas e o jogador ou dupla tirarem seis no dado, eles deverão voltar uma casa, e assim por diante. O jogo poderá continuar se os outros participantes quiserem disputar o segundo e terceiro lugares.

\section{Jogando e fazendo uma leitura crítica do jogo}

Respeitadas as etapas metodológicas propostas pelo grupo de pesquisa, chega o momento de o jogo passar pelo primeiro crivo dos adolescentes.

Durante o jogo realizado em duplas (um menino e uma menina), os adolescentes decidiram que as questões sobre assuntos como métodos contraceptivos, gravidez, por serem do universo feminino, deveriam ser respondidas por meninas. A intervenção dos pesquisadores nesse momento foi a de sugerir que os meninos é que deveriam responder, podendo, antes, discutir a resposta com a menina. A sugestão foi aceita pelo grupo e motivou o diálogo e troca de informações, contribuindo para reforçar a perspectiva interativa que o jogo pode despertar, e exemplificando a importância do papel do coordenador como mediador no processo ensinoaprendizagem (FREIRE, 1974). No espaço da saúde, Stotz e Valla (1994) sugerem que os profissionais de saúde sejam agentes facilitadores e mobilizadores, possibilitando o intercâmbio entre o saber científico e o popular (BRICEÑO-LEÓN, 1996). Torres, Hortale e Schall (2003) destacam as vantagens citadas pelos profissionais de saúde que trabalham com jogos educativos, dentre elas, a contribuição para a formação técnica da equipe multiprofissional. Tal recomendação foi incluída no manual de instruções que acompanha o jogo e que poderá auxiliar os professores e profissionais de saúde no uso do material.

Durante o processo, foi criado um espaço descontraído e prazeroso. Segundo Schall (2000), este ambiente é fundamental para maximizar os potenciais que facilitam a dinamização do conhecimento. Ao desenvolverem uma atividade lúdico-pedagógica, mediada pelo uso de um jogo, junto a puérperas, Fonseca, Scochi e Mello (2002) apontam que a descontração da brincadeira e do ato de jogar garantiu a liberdade verbal, diminuindo o medo das mães de expressarem suas dúvidas e anseios. Postura semelhante foi percebida em nosso estudo. Ao constatarem que as dúvidas, os anseios e curiosidades eram compartilhados por outros membros do grupo, os adolescentes se sentiam mais a vontade para expressar opiniões, fazer questionamentos e relatar experiências.

\section{Considerações finais}

O final do processo evidenciou que é possível o desenvolvimento de atividades de educação em saúde, de maneira descontraída e criativa, estimulando a participação efetiva do público-alvo e tratando-os como sujeitos históricos, e não como "caixas vazias". A participação juvenil é uma estratégia eficaz de promoção do desenvolvimento, uma vez que fortalece a autoestima, a assertividade e a construção do projeto de vida. Nos serviços de saúde, a participação ativa e autônoma de adolescentes e jovens no planejamento, na execução e na avaliação das ações contribui decisivamente para a eficácia, a resolução e o impacto social delas (BRASIL, 2005). 
Nogueira, M. J. et al.

É importante que os serviços de saúde reflitam sobre o seu papel frente às iniciativas juvenis, considerando sua responsabilidade de promover a saúde no âmbito comunitário, bem como reconhecer seu papel educativo em relação aos adolescentes e jovens. Segundo Ruzany (2008), para que seja possível outro enfoque sobre o adolescente, é preciso que a sociedade valorize seu potencial de contribuição e o apoie, permitindo que seus pensamentos, desejos, ideias e críticas sejam ouvidos. Uma vez que existe uma barreira cultural, na sociedade brasileira, de se tratar sexo e sexualidade nas esferas da família e da escola - campos que deveriam proporcionar a abertura ao diálogo sobre o tema -, o jogo potencializa a conversa a respeito do assunto entre os próprios adolescentes, baseando-se em informações científicas de qualidade.

Segundo Brougère (2002), o jogo em si não é uma situação educativa, mas ele pode gerar uma experiência com efeitos educativos. No presente estudo, o jogo não é tido como um fim em si mesmo, mas, antes, um instrumento para potencializar a comunicação e a reflexão entre adolescentes e os profissionais de saúde, os pais e os educadores.

Tal potencialidade estaria ligada menos ao caráter informativo do material produzido, mas, sobretudo, à dialogicidade, tanto no âmbito do processo de produção quanto no uso do material, que atuaria no sentido de reforçar o vínculo entre profissionais de saúde e usuários, no caso específico, os adolescentes. Na obra "Por uma pedagogia da pergunta", Freire (1985) demonstra a importância de se trabalhar o vínculo no processo de aprendizagem. No campo da sexualidade, pode-se utilizar o recurso dos jogos para problematizar e polemizar a respeito das práticas e vivências dos adolescentes. A criação de um espaço lúdico contribui para a construção do conhecimento, bem como para ampliar a possibilidade da instauração de novos vínculos entre os profissionais da saúde e os adolescentes.

\section{Referências}

ABDUCH, C. Grupos operativos com adolescentes. In: BRASIL. Cadernos juventude, saúde e desenvolvimento. Brasília: Ministério da Saúde, Secretaria de Políticas de Saúde, 1999. v. 1. p. 289-300.

AFONSO, M. L. M. Oficinas em dinâmicas de grupo na área da saúde. Belo Horizonte: Campo Social, 2003.

A polêmica sobre adolescência e sexualidade. Belo Horizonte: Campo Social, 2001.

ALTMANN, H. Orientação sexual nos parâmetros curriculares nacionais. Estudos Feministas, Florianópolis, v. 9, n. 2, p. 575-585, 2001.

AMARO, S. et al. Kalèdo, a new educational board-game, gives nutritional rudiments and encourages healthy eating in children: a pilot cluster randomized trial. European Journal of Pediatrics, Berlin, v. 165, n. 9, p. 630-635, 2006. 
Criação compartilhada de um jogo: ...

AVEDON, E. M.; SUTTON-SMITH, B. The study of games. New York: John Wiley, 1971.

BORUCHOVITCH, E. Fatores associados a não utilização de anticoncepcionais na adolescência. Revista de Saúde Pública, São Paulo, v. 26, n. 6, p. 437-443, 1992.

BRANDÃO, C. R. (Org.). Pesquisa participante. 5. ed. São Paulo: Brasiliense, 1985.

BRASIL. Ministério da Educação e Cultura. Parâmetros curriculares nacionais: temas transversais. Brasília: MEC/SEF, 1998a.

Ministério da Educação e Cultura. Parâmetros curriculares nacionais: terceiro e quarto ciclos do ensino fundamental; introdução aos parâmetros curriculares nacionais. Brasília: MEC/SEF, 1998b.

- Ministério da Saúde. Secretaria de Atenção à Saúde. Saúde integral de adolescentes e jovens: orientações para a organização de serviços de saúde. Brasília: Ministério da Saúde, 2005.

BRICEÑO-LEÓN, R. Siete tesis sobre la educación sanitaria para la participación comunitaria. Cadernos de Saúde Pública, Rio de Janeiro, v. 12, n. 1, p. 7-30, 1996.

BROUGÈRE, G. Jeu et loisir comme espaces d'apprentissages informels. Education et Sociétés, Louvain-la-Neuve, v. 2, n. 10, p. 5-20, 2002.

BUENO, S. M. V. Educação preventiva em sexualidade, DST-AIDS e drogas nas escolas: pesquisa ação e o compromisso social. 2001. 263f. Tese (Livre docência) - Escola de Enfermagem, Universidade de São Paulo, Ribeirão Preto, 2001.

CRUZ, T. M.; CARVALHO, M. P. Jogos de gênero: o recreio numa escola de ensino fundamental. Cadernos Pagu, Campinas, n. 26, p. 113-143, 2006.

FONSECA, L. M. M.; SCOCHI, C. G. S.; MELLO, D. F. Educação em saúde de puérperas em alojamento conjunto neonatal: aquisição de conhecimento mediado pelo uso de um jogo educativo. Revista Latino-Americana de Enfermagem, Ribeirão Preto, v. 10, n. 2, p. 166-171, 2002.

FREIRE, P. Ação cultura para a liberdade e outros escritos. Rio de Janeiro: Paz e Terra, 1976.

Educação como prática da liberdade. Rio de Janeiro: Paz e Terra, 1974.

Por uma pedagogia da pergunta. 3. ed. Rio de Janeiro: Paz e Terra, 1985.

GUIMARÃES, A. M. D. N.; VIEIRA, M. J.; PALMEIRA, J. A. Informações dos adolescentes sobre métodos anticoncepcionais. Revista Latino-Americana de Enfermagem, Ribeirão Preto, v. 11, n. 3, p. 293-298, 2003.

HERCOWITZ, A. Gravidez na adolescência. Pediatria Moderna, São Paulo, v. 38, n. 8, p. 392-395, 2002. 
Nogueira, M. J. et al.

HERNÁNDEZ, R. H. Conocimientos sobre sexualidad humana en jóvenes de 18 a 20 años de edad de ambos sexos que trabajan: un estudio desde la perspectiva de los procesos de socialización. Adolescencia y Salud, San Jose, v. 2, n. 2, p. 42-54, 2000. Disponível em: $<$ http://www.binasss.sa.cr/revistas/ays/2n2/1072.htm>. Acesso em: 10 nov. 2008.

HUIZINGA, J. Homo ludens: o jogo como elemento da cultura. São Paulo: Perspectiva, 1981.

INSTITUTO BRASILEIRO DE GEOGRAFIA E ESTATÍSTICA. Censo demográfico. Brasília: IBGE, 2001. Disponível em: http://www.ibge.gov.br/. Acesso em: 10 dez. 2008.

KISHIMOTO, T. M. Jogo, brinquedo, brincadeira e a educação. São Paulo: Cortez, 2008.

MACEDO, L. Os jogos e sua importância na escola. Cadernos de Pesquisa, São Paulo, n. 93 , p. 5-11, 1995.

MACHADO, M. F. A. S. et al. Integralidade, formação de saúde, educação em saúde e as propostas do SUS; uma revisão conceitual. Ciência \& Saúde Coletiva, Rio de Janeiro, v. 12 , n. 2, p. 335-342, 2007.

MITCHELL, A.; SAVILL-SMITH, C. The use of computer and video games for learning: a review of the literature. London: Learning, Learning and Skills Development Agency, 2004. Disponível em: https://crm.lsnlearning.org.uk/user/

login. asp $?$ ?code $=041529 \& \mathrm{P}=041529 \mathrm{PD} \&$ action $=$ pdfdl\&src $=\mathrm{XOWEB}>$. Acesso em: 12 jun. 2008.

MOHR, A. Análise do conteúdo de "saúde" em livros didáticos. Ciência \& Educação, Bauru, v. 6, n. 2, p. 89-106, 2000.

MONTEIRO, S.; REBELLO, S.; SCHALL, V. Jogando e aprendendo a viver: uma abordagem da Aids e das drogas através de recursos educativos. In: ACSELRALD, G. (Org.). Drogas e aids: estratégias de redução de danos. São Paulo: Hucitec, 1994. p. 13346.

NOGUEIRA, M. J. O que você vai ser quando crescer: sexualidade, gênero e maternidade adolescente. 2003. 121f. Dissertação (Mestrado em Sociologia) - Faculdade de Filosofia e Ciências Humanas, Universidade Federal de Minas Gerais, Belo Horizonte, 2003.

OLIVEIRA, M. C. F. A.; BILAC, E. D.; MUZSKAT, M. Homens e anticoncepção: um estudo sobre duas gerações masculinas das "camadas médias" paulistas. In: ENCONTRO NACIONAL DE ESTUDOS POPULACIONAIS, 12., 2000, Caxambu. Anais... Belo Horizonte: ABEP, 2000. Disponível em: <http://abep.org.br/usuario/

GerenciaNavegacao.php?caderno_id=187\&nivel=2>. Acesso em: 20 abr. 2008.

PAPERNY, D. M.; STARN, J. R. Adolescent pregnancy prevention by health education computer games: computer-assisted instruction of knowledge and attitudes. Pediatrics, Elk Grove Village, v. 83, n. 5, p. 742-752, 1989. 
Criação compartilhada de um jogo: ...

PICHON-RIVIÈRE, E. O processo grupal. São Paulo: Martins Fontes, 2000.

PINTO, H. D. S. A individualidade impedida: adolescência e sexualidade no espaço escolar. In: AQUINO, J. G. (Org.). Sexualidade na escola: alternativas teóricas e práticas. 3. ed. São Paulo: Summus, 1997. p. 97-105.

PORTELLA, A. P. et al. Homens: sexualidades, direitos e construção da pessoa. Recife: SOS Corpo, 2004.

RENA, L. C. B. Ações educativas em sexualidade: limites e possibilidades da intervenção psicossociológica em grupos de adolescentes. 1999. 233f. Dissertação (Mestrado em Psicologia Social) - Faculdade de Filosofia e Ciências Humanas, Universidade Federal de Minas Gerais, Belo Horizonte, 1999.

RESTREPO, H. M. Promoción de la salud: como construir vida saludable. Bogotá: Editora Médica Internacional, 2001.

RUZANY, M. H. Atenção à saúde do adolescente: mudança de paradigma. In: RUZANY, M. H; GROSSMAN, E. (Orgs.). Saúde do adolescente: competências e habilidades. Brasília: Ministério da Saúde, 2008. p. 21-25.

SALLAS, L. F.; QUINTANA, A. M. A sexualidade enquanto tema transversal: educadores e suas representações. Cadernos de Educação Especial, Santa Maria, v. 1, n. 19, p. 4-12, 2002.

SCHALL, V. T. A prevenção de DST/Aids e do uso indevido de drogas a partir da préadolescência: uma abordagem lúdico-afetiva. In: ACSELRALD, G. (Org.). Avessos do prazer: drogas, aids e direitos humanos. Rio de janeiro: Fiocruz, 2000. p. 184-214.

Educação em saúde no contexto brasileiro: influências sócio-históricas e tendências atuais. Educação em Foco, Belo Horizonte, v. 1, n. 1, p. 41-58, 2005.

SCHALL, V.; MONTEIRO, S.; REBELLO, S.; TORRES, M. Evaluation of the Zig-Zaids game: an entertaining educational tool for HIV/AIDS prevention. Cadernos de Saúde Pública, Rio de Janeiro, v. 15, supl. 2, p. 107-119, 1999.

SILVA, L. I. C. et al . Diferenças de gêneros nos grupos de brincadeira na rua: a hipótese de aproximação unilateral. Psicologia: Reflexão e Crítica, Porto Alegre, v. 19, n. 1, p. 114-121, 2006.

SILVA, M. P.; CARVALHO, W. L. P. O estudo do tratamento da informação nos livros didáticos das séries iniciais do ensino fundamental. Ciência \& Educação, Bauru, v. 11, n. 1, p. 171-184, 2005.

STOTZ, E. N.; VALLA, V. V. Saúde pública e movimentos sociais em busca do controle do destino. In: VALLA, V. V.; STOTZ, E. N. (Orgs.). Educação, saúde e cidadania. Petrópolis: Vozes, 1994. p. 123-141.

TORRES, H. C.; HORTALE, V. A.; SCHALL, V. A experiência de jogos em grupos 
Nogueira, M. J. et al.

operativos na educação em saúde para diabéticos. Cadernos de Saúde Pública, Rio de Janeiro, v. 19, n. 4, p. 1039-1047, 2003.

VILLELA, W. V.; ARILHA, M. Sexualidade, gênero e direitos sexuais e reprodutivos. In: BERQUÓ, E. (Org.). Sexo \& vida: panorama da saúde reprodutiva no Brasil. São Paulo: Ed. Unicamp, 2003. p. 95-150.

VYGOTSKY, L. S. Formação social da mente. São Paulo: Martins Fontes, 1984.

WEREBE, M. J. G. Sexualidade, política e educação. Campinas: Autores Associados, 1998.

WIDEMAN, H. H. et al. Unpacking the potential of educational gaming: a new tool for gaming research. Simulation \& Gaming, Thousand Oaks, v. 38, n. 1, p. 10-30, 2007.

Artigo recebido em 02/09/2010. Aceito em 18/02/2011. 